\title{
APLIKASI PENELITIAN DAN PENGABDIAN MASYARAKAT PADA UNIVERSITAS MULIA KAMPUS KOTA SAMARINDA BERBASIS WEB
}

\section{WEB BASED RESEARCH AND COMMUNITY DEDICATION MONITORING APPLICATION IN MULIA UNIVERSITY SAMARINDA CITY}

\author{
Ivan Leonard Tandi ${ }^{*}$, Tina Tri Wulansari ${ }^{2}$, Nariza Wanti Wulan Sari ${ }^{3}$ \\ ${ }^{1,2,3}$ Universitas Mulia, Samarinda, Kalimantan Timur \\ *E-mail: ivanleonard78@gmail.com
}

\begin{abstract}
ABSTRAK
Pada Universitas Mulia Kampus Kota Samarinda, data-data penelitian maupun pengabdian masih dikelola secara manual, pencatatan data masih dilakukan secara terpisah, pada proses pengumpulan data penelitian masih harus menemui dosen terkait. Hal ini dapat mengakibatkan terjadinya kesalahan seperti pencatatan data penelitian yang terpisah sehingga saat mengirimkan berkas data yang dikirimkan tidak lengkap. Karena itu proses digitalisasi merupakan hal yang sangat penting untuk proses penelitian dan pengabdian masyarakat pada Universitas. Aplikasi yang dibuat menggunakan metode prototype. Alat bantu yang digunakan dalam merancang sistem adalah use case diagram, class diagram, activity diagram dan sequence diagram. Pembuatan aplikasi menggunakan bahasa pemograman javascript, database menggunakan mysql, dan pengujian menggunakan black box testing. Aplikasi yang dibuat ini dapat memproses rekapitulasi data agar menjadi terdigitalisasi, monitoring penelitian dapat dilakukan secara online, dan penginputan data penelitian dan pengabdian masyarakat dapat dilakukan dimana saja dan kapan saja.
\end{abstract}

Kata kunci:Berbasis Web; Prototype; Penelitian dan Pengabdian Masyarakat;

\begin{abstract}
At Mulia University Samarinda City, research and community dedication data are still managed manually, recording data still conducted separately. In the process of data collection research still need to see a relevant lecturer. This could result in errors such as separate research recordedrs that when sending out data files sent out incomplete. Therefore, the digitalization process is crucial to the research and community dedication to the University. The application was created using the Prototype method. An aid used in designing system models is use case diagram, class diagram, activity diagram and sequence diagram. The application is created using javascript programming languages, database using mysql, and testing system using black box. Of the application it is hoped that recording data is to be digitalized, research and community dedication process can be done by online, and process insert data of research and community dedication can be done anywhere and at any time.
\end{abstract}

Keywords: Web Based; Prototype; Research and Community Dedication;

\section{PENDAHULUAN}

Untuk membantu meningkatkan akreditasi, Badan Akreditasi Nasional Perguruan Tinggi (BANPT) mengeluarkan instrumen yang mana salah satunya menitikberatkan pada pencapaian dan luaran tridharma yang berisi bobot yang menilai pada penelitian, pengabdian dan penunjang yang dilakukan oleh dosen tetap pada sebuah instansi.

Pada Universitas Mulia Kampus Kota Samarinda, pada proses penelitian maupun pengabdian yang terjadi saat ini masih dikelola secara manual, pencatatan data masih dilakukan 
secara terpisah. Lalu pada proses pengumpulan data penelitian juga masih harus menemui dosen terkait. Hal ini tentu saja dapat mengakibatkan terjadinya kesalahan seperti pencatatan data penelitian yang terpisah sehingga saat mengirimkan berkas ke Universitas Mulia Balikpapan, sehingga data yang dikirimkan tidak lengkap. Dapat dikatakan bahwa proses digitalisasi merupakan hal yang sangat penting untuk proses penelitian dan pengabdian masyarakat pada Universitas. Oleh karena itu, peneliti ingin membantu dan memberikan solusi dengan membuat aplikasi yang berjudul "Aplikasi Monitoring Penelitian dan Pengabdian Masyarakat pada Universitas Mulia Kampus Kota Samarinda Berbasis Web". Dari aplikasi yang dibuat dapat membantu proses rekapitulasi data menjadi terdigitalisasi, proses monitoring penelitian dapat dilakukan secara online, dan proses penginputan data penelitian dan pengabdian masyarakat dapat dilakukan dimana saja dan kapan saja.

Ada beberapa penelitian terdahulu yang membahas dengan tema serupa yang digunakan peneliti sebagai referensi dalam membua penelitian, yaitu Aditama, Wicaksono, dan Pradana menjelaskan rancangan sistem untuk mengatasi perhitungan angka kredit, pengurangan waktu proses menjadi 5-10 menit, dan menerapkan sistem untuk mengatasi masalah dari kurangnya inisiatif dosen dalam menyerahkan berkas penelitian [1]. Ratnasari dan Tawakal menjelaskan tentang membangun sistem informasi kegiatan penelitian dan pengabdian masyarakat agar dapat mempermudah proses pembuatan laporan, pencarian dan pengolahan data terkait penelitian dan pengabdian [2]. Dalis menjelaskan membuat sistem berbasis web untuk pengelolaan dan mengorganisir data-data terkait penelitian dan pengabdian masyarakat yang dilakukan oleh dosen di dalam lingkungan Akademik BSI (Bina Sarana Informatika) [3].

Adapun tujuan dari penelitian ini adalah untuk mendigitalisasi proses monitoring penelitian dan pengabdian masyarakat, membantu admin Lembaga Pengembangan, Penelitian, dan Pengabdian kepada Masyarakat (LP3M) dalam melakukan rekapitulasi data penelitian dan pengabdian, dan agar dosen dapat menginput data penelitian dimana saja dan kapan saja pada Universitas Mulia Kampus Kota Samarinda.

\section{METODOLOGI}

Metode pengembangan sistem yang digunakan adalah metode pengembangan sistem prototype. Berdasarkan [4] metode prototype memungkinkan terjadinya interaksi antar pengembang sistem dengan pengguna sistem, sehingga dapat mengatasi ketidakserasian antara pengembang dan pengguna. Adapun langkah-langkah dalam metode prototype yaitu :

1. Pengumpulan Kebutuhan

Tahap ini dilakukan Pengumpulan kebutuhan yaitu pengumpulan data-data serta informasi yang dibutuhkan dalam melakukan perancangan sistem.

2. Perancangan

Tahap kedua, dilakukan pembuatan rancangan untuk memberikan gambaran awal dari sistem yang akan dibuat, rancangan yang dibuat berupa struktur data, tampilan antar muka atau User Interface (UI) dari aplikasi dan alur proses dari sistem.

\section{Evaluasi Prototyping}

Tahap ketiga, Evaluasi akan dilakukan terhadap hasil rancangan yang telah dibuat, apakah rancangan yang dibuat sudah sesuai dengan keinginan dan kebutuhan user atau belum. Jika belum sesuai maka dapat mengulang tahapan sebelumnya untuk dapat melakukan perubahan yang sesuai dengan keinginan user. Jika telah sesuai maka dapat melanjutkan pada tahap selanjutnya.

4. Mengkode Sistem

Hasil prototype yang telah disetujui akan mulai dibuat menggunakan bahasa pemrograman yang telah ditentukan sebelumnya.

\section{Menguji Sistem}

Sistem yang telah selesai dibuat akan diuji terlebih dahulu oleh pengembang sebelum digunakan untuk mencari kekurangan sistem sehingga dapat diperbaiki.

\section{Evaluasi Sistem}

Setelah di uji sistem akan dievaluasi oleh end-user apakah sistem yang telah dibuat sesuai dengan yang diharapkan. Jika belum sesuai maka dapat mengulangi tahap ke 2.8.4 dan 2.8.5, jika sistem sudah sesuai dengan keinginan maka sistem sudah dapat digunakan. 7. Menggunakan Sistem

Sistem yang telah di evaluasi dan tidak memiliki kekurangan maka telah dapat digunakan. 


\section{HASIL DAN PEMBAHASAN}

1. Gambaran Umum Sistem yang Berjalan

Dari hasil observasi dan wawancara yang telah dilakukan oleh penulis, maka dapat diketahui bahwa saat ini pengajuan berkas proposal penelitian atau pengabdian masih secara langsung atau menggunakan email, proposal yang diterima harus dinilai secara manual apakah sesuai dengan kaidah penulisan atau tidak, Jika berkas proposal tidak memenuhi kaidah penulisan dan Rencana Induk Penelitian (RIP), maka berkas akan diserahkan kembali ke dosen terkait, jika berkas proposal memenuhi syarat, maka admin LP3M akan mengajukan berkas ke Universitas Mulia Balikpapan melalui via email, Setelah Universitas Mulia Balikpapan mengumumkan hasil seleksi, lalu admin LP3M menyampaikan hasil kepada dosen terkait yang lolos seleksi, Berkas hasil penelitian atau pengabdian yang telah dibuat kemudian diserahkan ke admin LP3M secara manual atau via email.

\section{Evaluasi Sistem yang Berjalan}

Setelah penulis mempelajari dan menganalisa mempunyai permasalahan pada sistem yang sedang berjalan sebagai berikut :

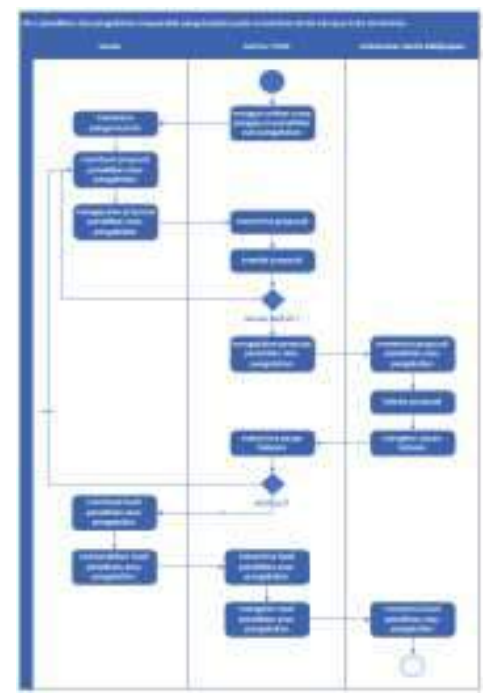

Gambar 1. Activity diagram penelitian dan pengabdian yang sedang berjalan

1. Dengan alur kegiatan yang berjalan saat ini pengajuan berkas proposal penelitian atau pengabdian masih secara langsung atau menggunakan email,

2. proposal yang diterima harus dinilai secara manual apakah sesuai dengan kaidah penulisan atau tidak Jika berkas proposal tidak memenuhi kaidah maka akan diserahkan kembali ke dosen terkait, jika memenuhi syarat, maka akan diajukan berkas ke Universitas Mulia Balikpapan melalui via email, lalu admin menyampaikan hasil kepada dosen terkait yang lolos seleksi,

3. Berkas hasil penelitian atau pengabdian yang telah dibuat kemudian diserahkan ke admin secara manual atau via email.

\section{Spesifikasi dan Perangkat}

Beberapa spesifikasi perangkat keras minimum dan perangkat lunak yang harus di pasang agar sistem ini berjalan dengan baik yaitu:

1. Spesifikasi perangkat keras minimum (hardware)

Spesifikasi perangkat keras minimum agar sistem ini dapat berjalan dengan lancer adalah :

a. Laptop Prosesor Intel Core i-3 gen 4 (setara atau lebih)

b. Memori RAM 2 GB (setara atau lebih)

c. Penyimpanan HDD 250 GB (setara atau lebih)

d. Layar monitor 14 inch (setara atau lebih)

2. Perangkat Lunak (software)

Sistem ini dikembangkan berbasis web yang dapat berjalan di semua flatform sistem operasi, ada beberapa perangkat lunak yang harus di pasang agar dapat menjalankan sistem ini:
a. Database MySQL
b. Web Server Apache
c. Browser (Google Crome atau Mozilla Firefox)

\section{Metode Pengembangan Sistem}

Metode pengembangan sistem yang digunakan pada penelitian ini adalah metode prototype. Tahapan yang harus dilakukan dalam perancangan sistem adalah sebagai berikut:

\section{1) Analisis Kebutuhan}

Dari hasil observasi dan wawancara yang dilakukan oleh penulis, maka dapat diketahui bahwa dapat diketahui bahwa proses penelitian dan pengabdian masih dilakukan secara manual.
2) Membangun Prototipe
A. Alur yang diusulkan 


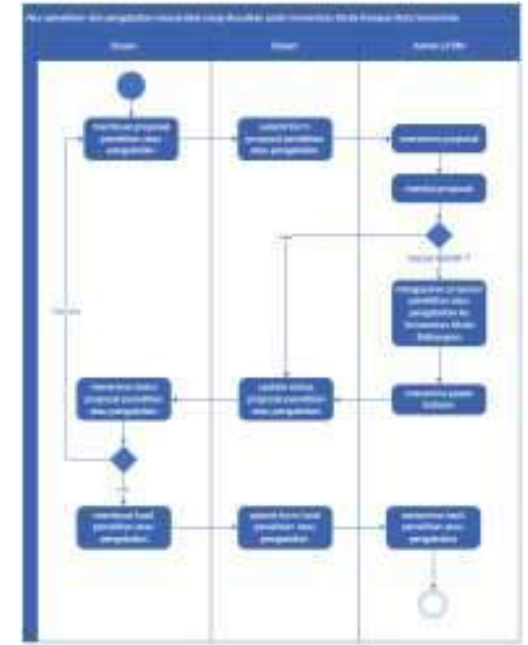

Gambar 2. Activity diagram penelitian dan pengabdian yang diusulkan

Perbedaan antara activity diagram yang diusulkan dengan activity yang sedang berjalan adalah terletak pada proses yang dilakukan. Pada sistem yang berjalan, proses pengajuan proposal penelitian dan pengabdian masih dilakukan secara manual atau via email, sedangkan pada sistem yang diusulkan telah dilakukan digitalisasi sehingga memudahkan admin maupun dosen dalam mengajukan proposal. Pada sistem yang berjalan pemberitahuan hasil pengajuan proposal masih dilakukan dengan penyampaian langsung ke dosen terkait, sedangkan pada sistem yang diusulkan dilakukan digitalisasi, sehingga dosen terkait dapat melihat secara langsung hasil pengajuan dari proposal. Proses pada sistem yang diusulkan juga sudah terkomputerisasi dengan menggunakan aplikasi berbasis web dan mempunyai tempat penyimpanan database.

Adapun langkah-langkah pada activity diagram yang diusulkan adalah sebagai berikut:

1. dosen menginput proposal ke sistem,

2. admin menerima proposal dan menilai apakah telah sesuai kaidah, jika iya maka akan diteruskan ke universitas mulia Balikpapan, jika tidak maka proposal akan ditolak,

3. setelah mendapat surat balasan dari universitas mulia Balikpapan, admin melakukan update status berupa setuju pada proposal,

4. dosen menerima hasil penilaian proposal, dan menginput hasil penelitian atau pengabdian ke dalam sistem.

B. Use Case Diagram
Berikut ini adalah gambaran secara umum tentang aplikasi monitoring penelitian dan pengabdian masyarakat pada universitas mulia kampus kota samarinda yang akan dibangun.

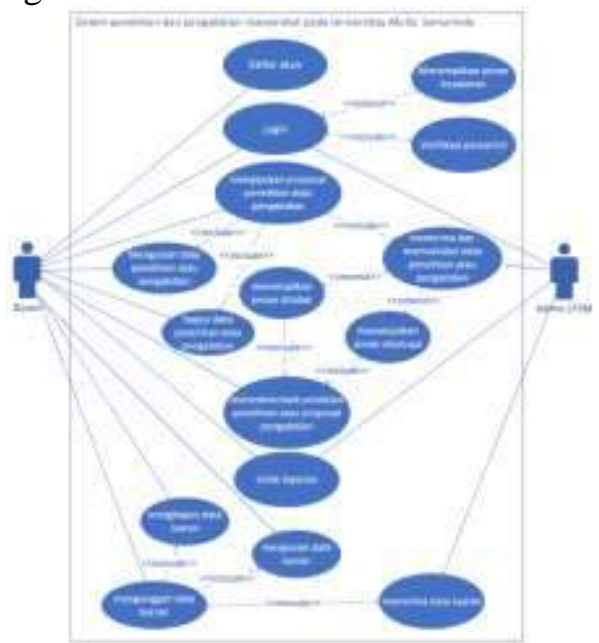

Gambar 3. Use Case Diagram (sistem usulan)

Dari gambar use case diagram diatas terdapat 2 (dua) aktor yang terlibat didalam sistem. Kedua aktor tersebut berperan sebagai dosen dan admin LP3M, aktor dosen dapat melakukan aktivitas seperti mendaftar akun, login, mengunggah data penelitian atau pengabdian, menerima hasil penilaian, mengubah data, menghapus data, cetak laporan, mengunggah data luaran, menghapus data luaran dan mengubah data luaran. Sedangkan aktor admin LP3M dapat melakukan aktivitas seperti login, menerima dan memvalidasi data penelitian atau pengabdian, cetak laporan dan menerima data luaran.

\section{Class Diagram}

Adapun gambar class diagram aplikasi monitoring penelitian dan pengabdian masyarakat pada universitas mulia kampus kota samarinda yang dibuat adalah sebagai berikut:

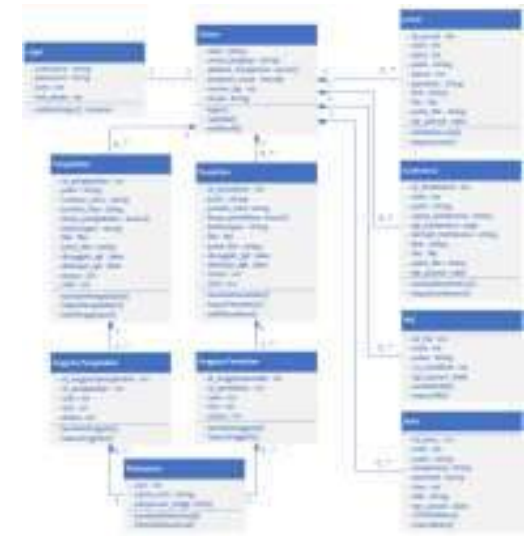

Gambar 4. Class Diagram (sistem usulan) 
D. Sequence Diagram

1. sequence diagram login

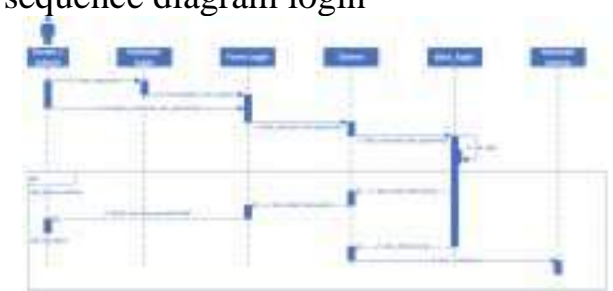

Gambar 5. Sequence Diagram Login

2. sequence diagram input data proposal penelitian

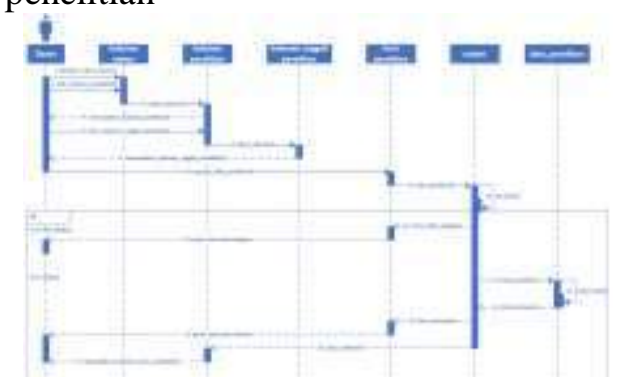

Gambar 6. Sequence Diagram Input Data Proposal Penelitian

\section{E. Activity diagram}

1. activity diagram proses penelitian pada sistem

Adapun activity diagram yang dibuat adalah sebagai berikut:

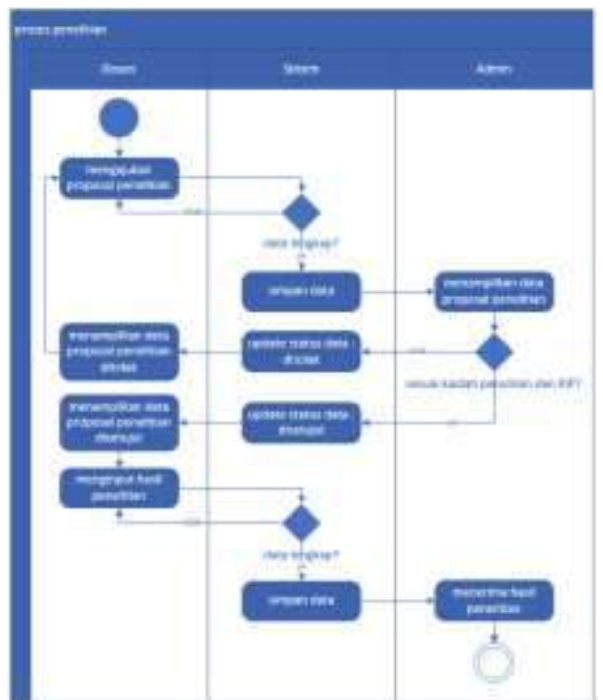

Gambar 7. Activity Diagram Proses Penelitian Pada Sistem

Penjabaran proses pada gambar activity diagram diatas adalah sebagai berkut:

1. Dosen mengajukan proposal penelitian secara online ke sistem,

2. Sistem memeriksa apakah data form diisi dengan lengkap, jika tidak maka sistem akan memberi pesan pemberitahuan kepada dosen bahwa form tidak lengkap, jika lengkap maka sistem akan menyimpan data form,

3. Admin menerima data proposal penelitian yang diajukan oleh dosen, lalu memvalidasi proposal apakah sudah sesuai kaidah penulisan dan Rencana Induk Penelitian (RIP), jika tidak sesuai maka proposal akan ditolak. Jika sesuai maka proposal akan disetujui,

4. Sistem menampilkan data hasil validasi proposal kepada dosen, jika data ditolak maka dosen harus mengajukan proposal penelitian kembali. Jika disetujui maka dosen akan melanjutkan penelitian dan menginput data hasil penelitian ke sistem,

5. Admin menerima data hasil penelitian.

3) Evaluasi Prototyping

Pada tahap ini dilakukan evaluasi terhadap rancangan tampilan user yang telah dibuat. Evaluasi yang tidak disetujui oleh user, yaitu Perubahan warna pada tabel agar menjadi lebih kontras, dan warna yang diusulkan adalah warna hijau.Rancangan tampilan user interface yang dibuat adalah sebagai berikut:

1. Rancangan Halaman Login

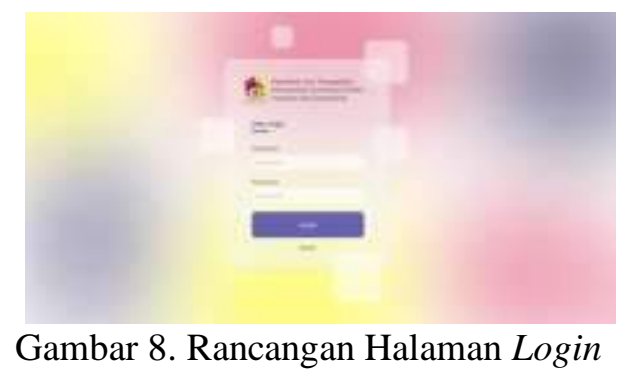

2. Rancangan menu utama dosen

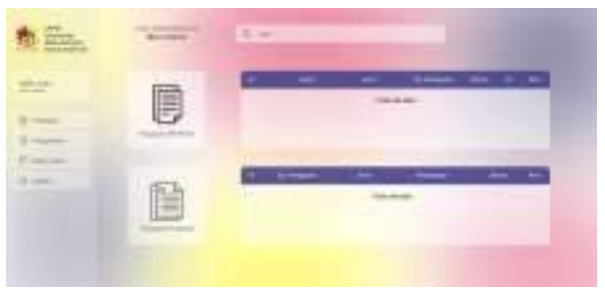

Gambar 9. Rancangan Menu Utama Dosen

4) Mengkodekan Sistem

Pada tahap ini, dilakukan pengkodean terhadap rancangan-rancangan yang telah dievaluasi pada tahap sebelumnya, maka dibutuhkan beberapa hal dalam membangun aplikasi monitoring penelitian dan pengabdian 
masyarakat pada universitas mulia kampus kota samarinda, sebagai berikut:

1. Bahasa Pemrograman

Bahasa pemrograman yang digunakan oleh peneliti adalah bahasa pemograman Javascript, proses frontend menggunakan HTML, CSS, javascript dengan library react.js, proses backend menggunakan node.js dengan framework express.js.

2. Basis Data

Basis data yang digunakan oleh peneliti adalah basis data MySQL.

3. Implementasi Antarmuka Program

Berikut ini adalah hasil implementasi dalam bentuk progam aplikasi monitoring penelitian dan pengabdian masyarakat dapat dilihat pada gambar berikut ini:

\section{Halaman Login}

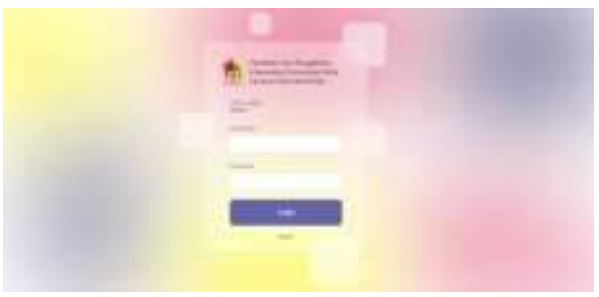

Gambar 10. Halaman Login

2. Halaman menu utama dosen

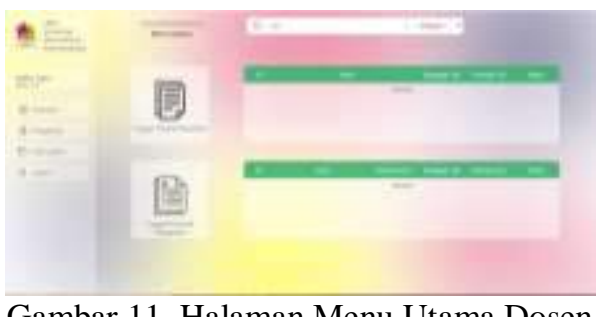

3. Halaman menu pengajuan penelitian

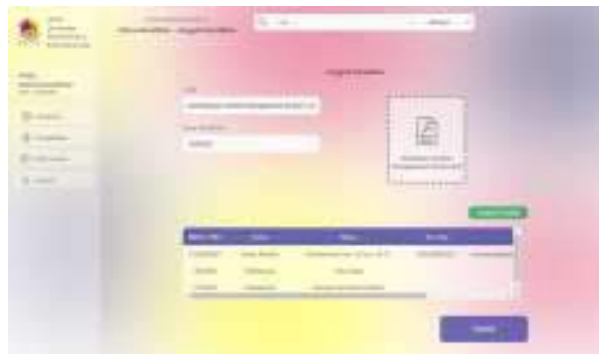

Gambar 12. Halaman Menu Pengajuan Penelitian

4. Halaman laporan penelitian dosen

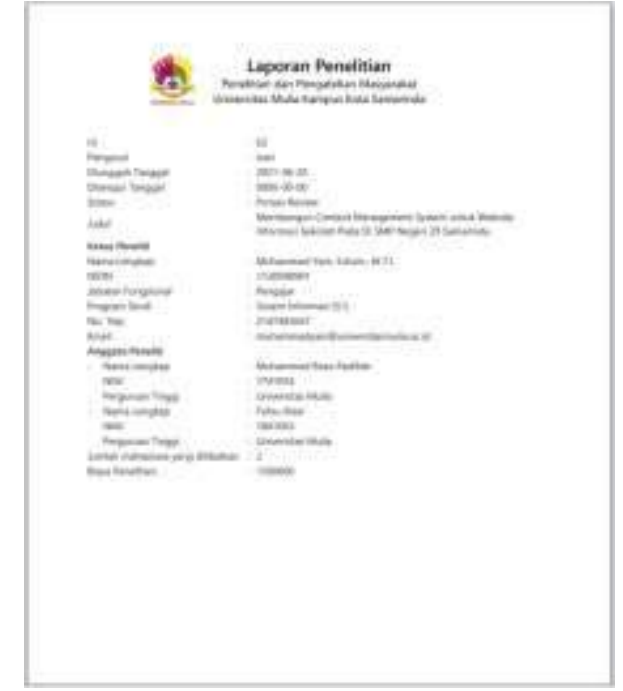

Gambar 13. Halaman laporan penelitian dosen

5. Halaman menu utama admin

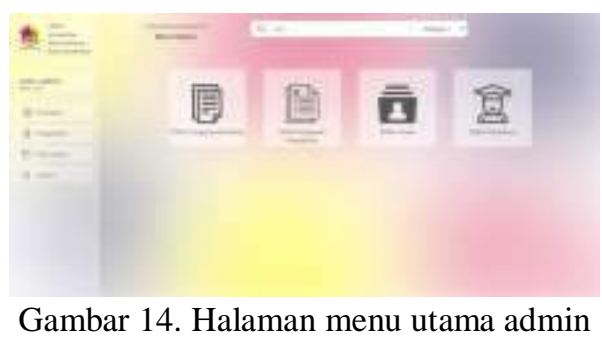

6. Halaman data penelitian admin

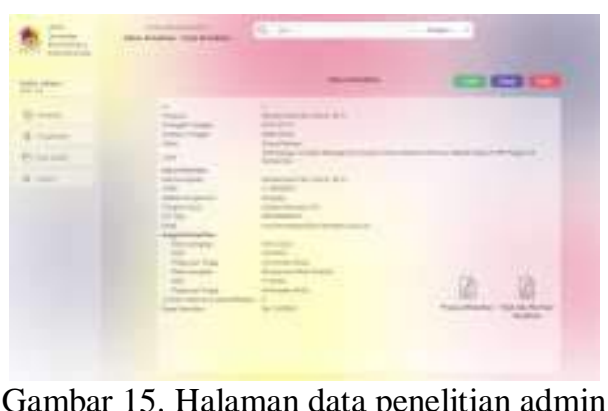

5) Menguji Sistem

Pada tahap ini, pengujian sistem menggunakan metode black box dan diuji oleh penelliti selaku pembuat aplikasi. Berikut adalah daftar tabel pengujian yang dilakukan:

1. Pengujian Halaman login

Tabel 1. Pengujian Halaman Login 
DOI: $10.47002 /$ seminastika.v3i1.255

\begin{tabular}{|c|c|c|c|c|c|c|}
\hline $\begin{array}{l}\text { Te } \\
s t \\
C a \\
s e \\
\text { Id }\end{array}$ & $\begin{array}{c}\text { Test } \\
\text { Case } \\
\text { Nam } \\
e\end{array}$ & $\begin{array}{l}\text { Test } \\
\text { Case }\end{array}$ & $\begin{array}{c}\text { Inpu } \\
t \\
\text { Data }\end{array}$ & $\begin{array}{c}\text { Expect } \\
\text { ed } \\
\text { Output }\end{array}$ & $\begin{array}{c}\text { Actu } \\
\text { al } \\
\text { Outp } \\
\text { ut }\end{array}$ & $\begin{array}{c}\text { Statu } \\
\mathrm{s}\end{array}$ \\
\hline 1 & $\begin{array}{l}\text { Vali } \\
\text { dasi } \\
\text { Logi } \\
n\end{array}$ & $\begin{array}{l}\text { Input } \\
\text { form } \\
\text { login } \\
\text { deng } \\
\text { an } \\
\text { akun } \\
\text { yang } \\
\text { telah } \\
\text { terda } \\
\text { ftar }\end{array}$ & $\begin{array}{l}\text { User } \\
\text { name } \\
: \\
\text { admi } \\
\text { n } \\
\text { Pass } \\
\text { word } \\
: \\
\text { pass } \\
\text { word }\end{array}$ & $\begin{array}{l}\text { Menga } \\
\text { rahkan } \\
\text { user ke } \\
\text { menu } \\
\text { utama }\end{array}$ & $\begin{array}{l}\text { Men } \\
\text { gara } \\
\text { hkan } \\
\text { user } \\
\text { ke } \\
\text { menu } \\
\text { utam } \\
\text { a }\end{array}$ & valid \\
\hline 2 & $\begin{array}{l}\text { Vali } \\
\text { dasi } \\
\text { Logi } \\
n\end{array}$ & $\begin{array}{l}\text { Input } \\
\text { form } \\
\text { login } \\
\text { deng } \\
\text { an } \\
\text { akun } \\
\text { yang } \\
\text { tidak } \\
\text { terda } \\
\text { ftar }\end{array}$ & $\begin{array}{l}\text { User } \\
\text { name } \\
: \\
\text { admi } \\
\text { n } \\
\text { Pass } \\
\text { word } \\
: \\
\text { pass } \\
\text { word }\end{array}$ & $\begin{array}{l}\text { Menam } \\
\text { pilkan } \\
\text { pesan } \\
\text { error } \\
\text { userna } \\
\text { me } \\
\text { atau } \\
\text { passwo } \\
\text { rd } \\
\text { salah }\end{array}$ & $\begin{array}{l}\text { Men } \\
\text { ampi } \\
\text { lkan } \\
\text { pesa } \\
\mathrm{n} \\
\text { error } \\
\text { user } \\
\text { name } \\
\text { atau } \\
\text { pass } \\
\text { word } \\
\text { salah }\end{array}$ & valid \\
\hline
\end{tabular}

Kasus dan Hasil Pengujian

Penjelasan dari tabel diatas adalah Username Password saat tombol login di tekan, maka akan masuk ke halaman utama, dan saat memasukan Username Password salah saat tombol login di tekan, maka akan tampil pesan error username atau password salah. Dari penjelasan diatas maka dapat disimpulkan bahwa sistem berjalan dengan baik dan sesuai dengan keinginan pengembang.

\section{Pengujian halaman penelitian dosen}

Tabel 2. Pengujian Halaman penelitian dosen

\begin{tabular}{|c|c|c|c|c|c|c|}
\hline $\begin{array}{l}\text { Te } \\
s t \\
C a \\
\text { se } \\
\text { Id }\end{array}$ & $\begin{array}{c}\text { Test } \\
\text { Case } \\
\text { Nam } \\
\quad e\end{array}$ & $\begin{array}{l}\text { Test } \\
\text { Case }\end{array}$ & $\begin{array}{c}\text { Inpu } \\
t \\
\text { Data }\end{array}$ & $\begin{array}{c}\text { Expect } \\
\text { ed } \\
\text { Output }\end{array}$ & $\begin{array}{c}\text { Actu } \\
\text { al } \\
\text { Outp } \\
\text { ut }\end{array}$ & $\begin{array}{c}\text { Statu } \\
\quad s\end{array}$ \\
\hline 1 & $\begin{array}{l}\text { Peng } \\
\text { ajuan } \\
\text { prop } \\
\text { osal } \\
\text { penel } \\
\text { itian }\end{array}$ & $\begin{array}{l}\text { Input } \\
\text { form } \\
\text { prop } \\
\text { osal } \\
\text { penel } \\
\text { itian } \\
\text { deng } \\
\text { an } \\
\text { leng } \\
\text { kap }\end{array}$ & $\begin{array}{l}\text { Judul } \\
: \\
\text { Mem } \\
\text { bang } \\
\text { un } \\
\text { Cont } \\
\text { ent } \\
\text { Man } \\
\text { agem } \\
\text { ent } \\
\text { Syste } \\
\text { m } \\
\text { untu } \\
\text { k } \\
\text { Web } \\
\text { site }\end{array}$ & $\begin{array}{l}\text { Menam } \\
\text { pilkan } \\
\text { pesan } \\
\text { data } \\
\text { berhasi } \\
1 \\
\text { disimp } \\
\text { an dan } \\
\text { mengar } \\
\text { ahkan } \\
\text { user ke } \\
\text { menu } \\
\text { peneliti } \\
\text { an }\end{array}$ & $\begin{array}{l}\text { Men } \\
\text { ampi } \\
\text { lkan } \\
\text { pesa } \\
\text { n } \\
\text { data } \\
\text { berh } \\
\text { asil } \\
\text { disi } \\
\text { mpa } \\
\text { n } \\
\text { dan } \\
\text { men } \\
\text { gara } \\
\text { hkan } \\
\text { user }\end{array}$ & valid \\
\hline
\end{tabular}

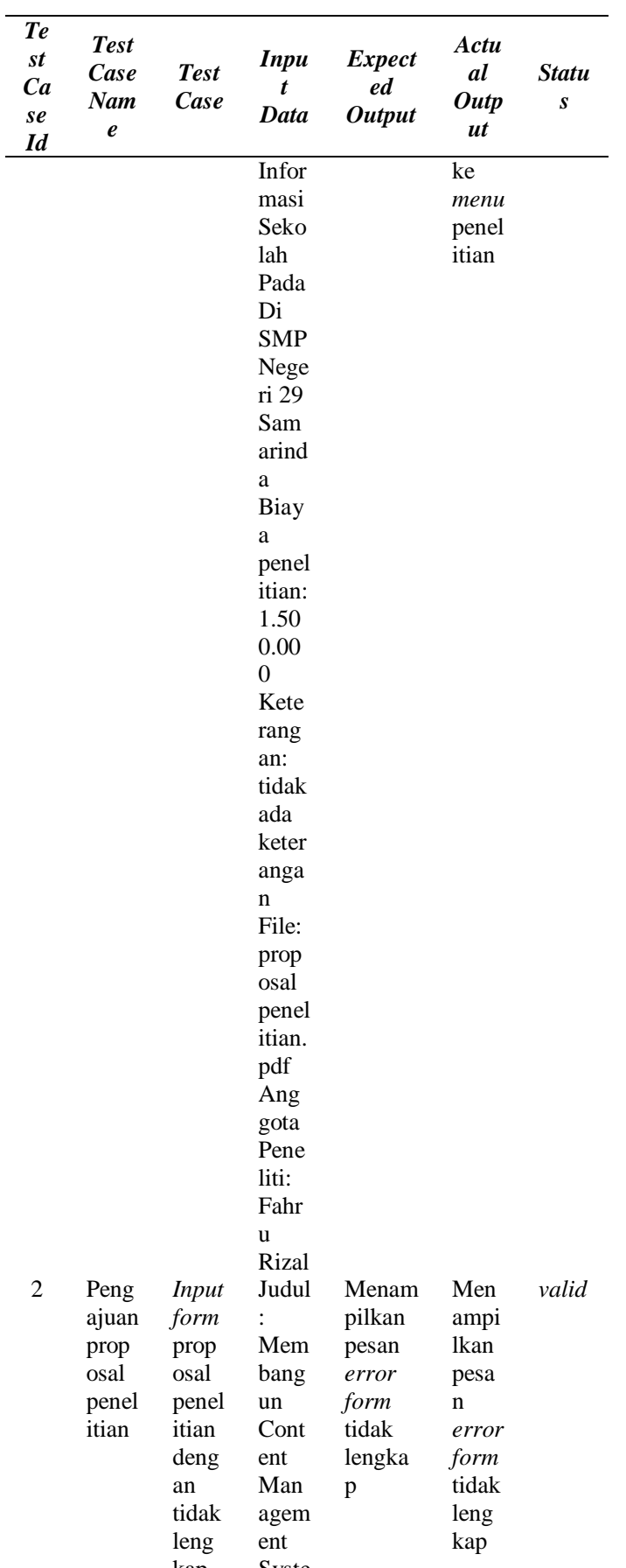

Syste

$\mathrm{m}$

untu

$\mathrm{k}$

Web

site

Infor

masi

Seko

lah

Pada

Di

SMP

Nege

ri 29

Sam

arind

a

Biay

a

penel

itian: 


\begin{tabular}{|c|c|c|c|c|c|c|}
\hline $\begin{array}{l}\text { Te } \\
s t \\
C a \\
s e \\
I d\end{array}$ & $\begin{array}{c}\text { Test } \\
\text { Case } \\
\text { Nam } \\
e\end{array}$ & $\begin{array}{l}\text { Test } \\
\text { Case }\end{array}$ & $\begin{array}{c}\text { Inpu } \\
t \\
\text { Data }\end{array}$ & $\begin{array}{c}\text { Expect } \\
\text { ed } \\
\text { Output }\end{array}$ & $\begin{array}{c}\text { Actu } \\
\text { al } \\
\text { Outp } \\
\text { ut }\end{array}$ & $\begin{array}{c}\text { Statu } \\
s\end{array}$ \\
\hline & & & $\begin{array}{l}1.50 \\
0.00 \\
0 \\
\text { Kete } \\
\text { rang } \\
\text { an: } \\
\text { tidak } \\
\text { ada } \\
\text { keter } \\
\text { anga } \\
\text { n }\end{array}$ & & & \\
\hline
\end{tabular}

Penjelasan tabel diatas adalah saat memasukan data form yang telah diisi lengkap saat submit di tekan, maka akan menampilkan pesan data berhasil disimpan dan mengarahkan user ke mеnu penelitian. Dan saat form yang diisi tidak lengkap saat submit di tekan, maka akan Menampilkan pesan error form tidak lengkap. Dari penjelasan diatas maka dapat disimpulkan bahwa sistem berjalan dengan baik dan sesuai dengan keinginan pengembang.

6)

Evaluasi Sistem

Pada tahap ini, pengujian sistem menggunakan metode black box dan diuji oleh admin selaku pengguna aplikasi. Tujuan evaluasi ini adalah untuk memastikan aplikasi yang dibuat telah memenuhi kebutuhan dalam monitoring penelitian dan pengabdian atau belum. Dan hasil dari pengujian yang dilakukan, aplikasi dapat berjalan dengan baik dan tidak ditemukan error atau bug, dan aplikasi dapat dilanjutkan ke tahap berikutnya.

7)

Menggunakan Sistem

Pada tahap ini aplikasi telah dibuat sesuai dengan kebutuhan dan keinginan pengguna, dan juga telah melewati tahap testing, tetapi aplikasi belum dilakukan implementasi pada Universitas Mulia Kampus Kota Samarinda.

\section{KESIMPULAN}

Berdasarkan penelitian yang telah dilakukan dan berbagai penjelasan yang telah diuraikan, maka dapat disimpulkan bahwa aplikasi yang dibuat berbasis web dan menggunakan bahasa pemograman javascript, dengan front-end menggunakan HTML, CSS dan react.js, back-end menggunakan node.js dan database menggunakan mysql. Alat bantu yang digunakan adalah use case diagram, class diagram, sequence diagram, dan activity diagram. Kemudian, proses pengujian aplikasi menggunakan metode black box. Aplikasi yang telah dibuat telah diuji dan dapat melakukan monitoring, rekapitulasi, dan penginputan data secara digitalisasi.

\section{SARAN}

Adapun saran yang diberikan adalah Agar sistem yang dibuat ini dapat berjalan dengan maksimal tentu perlu adanya dukungan infrastruktur jaringan yang baik dan sistem ini dapat dikembangkan lagi seiring bertambahnya kebutuhan akan proses yang terjadi pada penelitian dan pengabdian masyarakat

\section{UCAPAN TERIMA KASIH}

Dalam penyusunan jurnal ini terdapat kendala yang ditemui dalam penulisan, oleh karena itu penulis mengucapkan terima kasih kepada rekan-rekan dan dosen pembimbing yang telah membantu penulis dalam menyusun jurnal ini.

\section{DAFTAR PUSTAKA}

[1] M. S. P. Aditama, S. A. Wicaksono and F. Pradana, "Pembangunan Sistem Informasi Kenaikan Jabatan Fungsional Dosen Universitas Brawijaya," Jurnal Pengembangan Teknologi Informasi dan Ilmu Komputer, vol. 2, no. 10, pp. 35383544, 2018.

[2] D. Ratnasari and H. A. Tawakal, "Analisis dan Perancangan Aplikasi SIstem Informasi Penelitian dan Pengabdian Masyarakat LPPM STT Terpadu Nurul Fikri," Teknik Informatika STT Terpadu Nurul Fikri, vol. 3, no. 1, pp. 1-5, 2017.

[3] S. Dalis, "Rancang Bangun Sistem Informasi Lembaga Penelitian Dan Pengabdian Masyarakat Berbasis Web," Paradigma - Jurnal Komputer dan Informatika, vol. 19, no. 1, pp. 1-8, 2017.

[4] I. Sommerville, Software Engineering Ninth Edition, Massachusetts: AddisionWesley, 2011. 